\title{
New Voltage Mode Universal Filters Using Only Two CDBAs
}

\author{
J. K. Pathak, ${ }^{1}$ A. K. Singh, ${ }^{2}$ and Raj Senani ${ }^{3}$ \\ ${ }^{1}$ Department of Electronics and Communication Engineering, Echelon Institute of Technology, Kabulpur, \\ Jasana-Manjawali Road, Faridabad, Haryana 121101, India \\ ${ }^{2}$ Department of Electronics and Communication Engineering, Faculty of Engineering and Technology, HRCT Group of Institutions, \\ 7th Km Stone, Meerut Road, Morta, Ghaziabad 201001, India \\ ${ }^{3}$ Division of Electronics and Communication Engineering, Netaji Subhas Institute of Technology, Sector-3, Dwarka, \\ New Delhi, Delhi 110078, India
}

Correspondence should be addressed to Raj Senani; senani@nsit.ac.in

Received 13 November 2012; Accepted 13 December 2012

Academic Editors: E. I. El-Masry, R. Luzzi, L.-F. Mao, and Y. Takahashi

Copyright (C) 2013 J. K. Pathak et al. This is an open access article distributed under the Creative Commons Attribution License, which permits unrestricted use, distribution, and reproduction in any medium, provided the original work is properly cited.

\begin{abstract}
Two new configurations for voltage mode universal filters (VMUFs) using only two current differencing buffered amplifiers (CDBAs) are proposed. Both of the new configurations can realize all the five standard types of the filters, namely, low pass (LP), high pass (HP), band pass (BP), band stop (BS), and all pass (AP), from the same topology. In contrast to previously known CDBA-based VMUFs, the new configurations do not need an additional active device for voltage inversion to realize all pass functions. The proposed configurations offer the tunability of the natural angular frequency $\left(\omega_{o}\right)$, quality factor $(Q)$, or the bandwidth (BW) through separate virtually grounded resistors. Moreover, both circuits have resistive input impedance (which can be made high) and a low output impedance to facilitate easy cascading without additional buffers. PSPICE simulation results, based upon commercially available AD844 ICs to implement the CDBA, are included which confirm the practical workability of the new VMUF configurations.
\end{abstract}

\section{Introduction}

Analog filters are widely used for continuous-time signal processing in communication, measurement, instrumentation, and control systems [1]. Universal biquadratic filters are particularly attractive since they can realize all the five standard types of the filters, namely, low pass (LP), high pass (HP), band pass (BP), band stop (BS), and all pass (AP), from the same topology.

Whereas universal voltage mode filters using current conveyors (CCs) or current feedback operational amplifiers (CFOAs) have received considerable attention in the technical literature, many of the reported circuits suffer from the drawbacks of requiring a large number of active and/or passive components and/or nonavailability of tuning of filter parameters [2].

Traditionally, the analog signal processing operations have been accomplished employing the voltage as signal variable. On the other hand, it has also been recognized that current mode circuits can achieve significant improvement in bandwidth, simplification of circuitry, power consumption, and dynamic range [3]. In order to maintain compatibility with existing voltage processing circuits as well as taking advantages of current mode circuits, a new active element called current differencing buffered amplifier (CDBA) was introduced in [4]. CDBA is suitable for IC implementation in both bipolar and CMOS technologies $[4,5]$. Since a CDBA operates in both current mode and voltage mode, along with current differencing feature, CDBA has been shown to offer a lot of flexibility in circuit design; for instance, see [5-26] and the references cited therein.

In this paper, two new CDBA-based voltage mode universal filters (VMUFs) are proposed which not only enlarge the previously known class of two CDBA-based VMUFs but also provide a number of advantages over the previously reported circuits. The workability of the proposed circuits has been demonstrated through PSPICE simulations. 


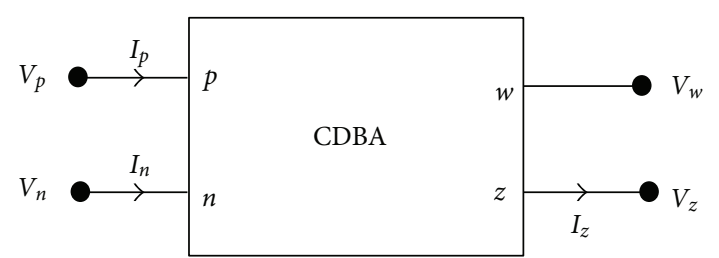

FIgURE 1: The symbolic notation of the CDBA.

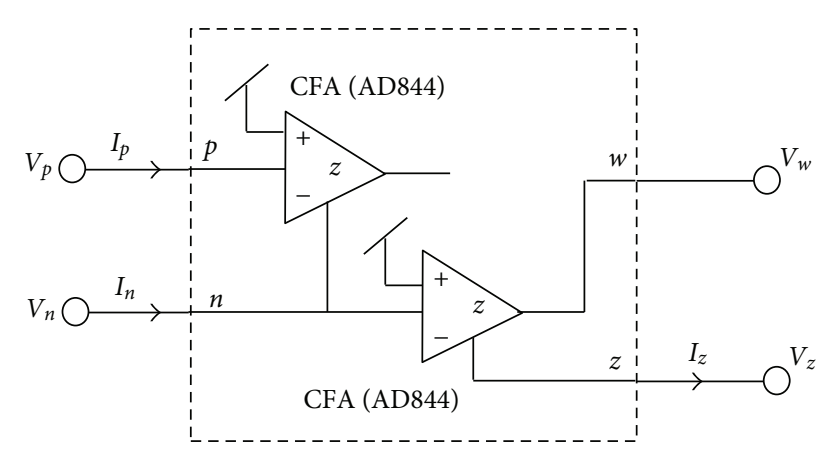

FIGURE 2: Implementation of the CDBA using commercially available CFOAs.

\section{The Proposed New VMUF Configurations}

The circuit symbol of the CDBA is shown in Figure 1. The terminals characteristics of the CDBA are given by

$$
\begin{gathered}
V_{p}=V_{n}=0, \quad I_{z}=I_{p}-I_{n}, \\
V_{W}=V_{Z} .
\end{gathered}
$$

The CDBA can be implemented in a number of ways; however, a popular realization $[6,7]$ based on the use of two commercially available CFOAs is shown here in Figure 2.

Figure 3 shows the proposed VMUF circuits based on CDBAs. From a straight forward circuit analysis, the output voltage function, natural angular frequency $\left(\omega_{o}\right)$, quality factor $(Q)$, bandwidth $(B W)$, gain factor, and the conditions required to realize different filters are shown in Table 1.

From Table 1, it is clear that both circuits can be used as a voltage mode three-input single-output universal filter that can realize all the standard types of filter functions. It is seen from Table 1 that resistive matching is required to realize only band stop and all pass filters.

Both circuits enjoy tuning of filter parameters by first adjusting $\omega_{o}$ by $R_{1}$ and/or $R_{3}$ then $Q_{o}$ or BW by $R_{4}$ after which gain factor $H_{o}$ (in case of LP and BP) can be controlled by adjusting $R_{2}$.

It may be noted that in contrast to previously known CDBA-based circuit [6], in the proposed circuits, any

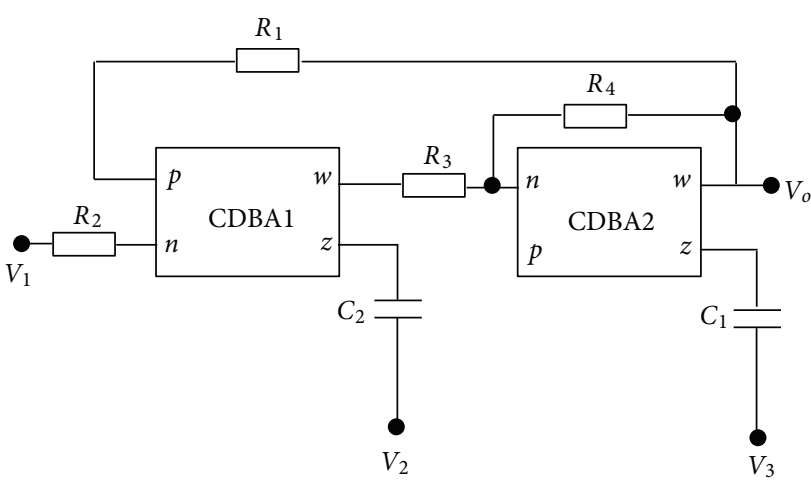

(a) Circuit 1

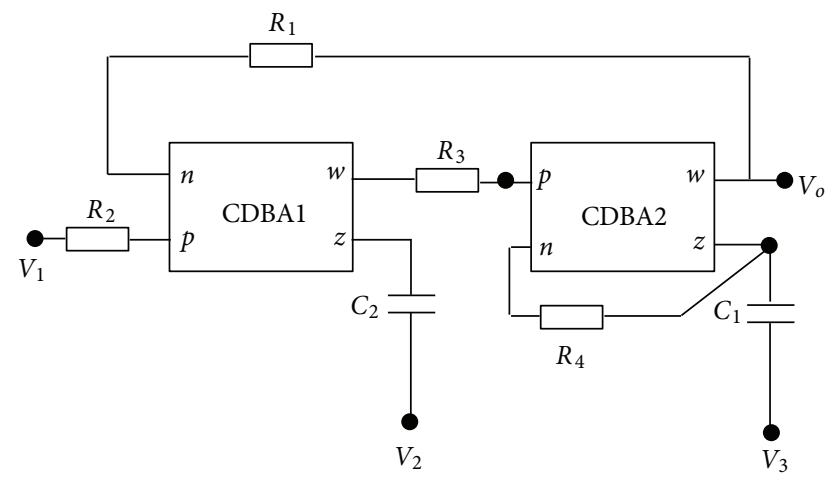

(b) Circuit 2

FIgURE 3: The proposed CDBA-based VMUF circuit configurations.

additional voltage inversion is not required to realize all pass function, thus resulting in the saving of one active element.

\section{Effects of the CDBA Nonidealities and Their Parasitic Impedances}

A practical CDBA can be described by the following relationships that take into account the nonidealities of the device:

$$
\begin{gathered}
V_{p}=V_{n}=0, \quad I_{z}=\beta_{p} I_{p}-\beta_{n} I_{n} \\
V_{W}=\alpha V_{z},
\end{gathered}
$$

where $\beta_{p}=1-\varepsilon_{p}$ and $\varepsilon_{p}\left(l \varepsilon_{p} l \ll 1\right)$ is the current tracking error from $p$-terminal to $z$-terminal, $\beta_{n}=1-\varepsilon_{n}$ and $\varepsilon_{n}\left(l \varepsilon_{n} l \ll 1\right)$ is the current tracking error from $n$-terminal to $z$-terminal, and $\alpha=1-\varepsilon_{v}$ and $\varepsilon_{v}\left(l \varepsilon_{v} l \ll 1\right)$ is the voltage tracking error from $z$-terminal to $w$-terminal of the CDBA.

In addition to the aforementioned, if we also consider parasitic impedances at $z$-terminal of CDBA as shown in Figure 4 and reanalyze VMUF circuits of Figure 3, we get the following results. 
TABLE 1: Results of the analysis of the proposed VMUF configurations.

\begin{tabular}{|c|c|c|}
\hline Parameters/functions & Circuit 1 & Circuit 2 \\
\hline$V_{o}$ & $\frac{s^{2} V_{3}-s V_{2} / C_{1} R_{3}+V_{1} / C_{1} C_{2} R_{2} R_{3}}{s^{2}+s / C_{1} R_{4}+1 / C_{1} C_{2} R_{1} R_{3}}$ & $\frac{s^{2} V_{3}-s V_{2} / C_{1} R_{3}+V_{1} / C_{1} C_{2} R_{2} R_{3}}{s^{2}+2 s / C_{1} R_{4}+1 / C_{1} C_{2} R_{1} R_{3}}$ \\
\hline \multicolumn{3}{|l|}{ For } \\
\hline LP & $\begin{array}{c}V_{3}=0, V_{2}=0, V_{1}=V_{i} \\
H_{0 \mathrm{LP}}=\frac{R_{1}}{R_{2}}\end{array}$ & $\begin{array}{c}V_{3}=0, V_{2}=0, V_{1}=V_{i} \\
H_{0 \mathrm{LP}}=\frac{R_{1}}{R_{2}}\end{array}$ \\
\hline HP & $\begin{array}{c}V_{3}=V_{i}, V_{2}=0, V_{1}=0 \\
H_{0 \mathrm{HP}}=1\end{array}$ & $\begin{array}{c}V_{3}=V_{i}, V_{2}=0, V_{1}=0 \\
H_{0 \mathrm{HP}}=1\end{array}$ \\
\hline BP & $V_{3}=0, V_{2}=V_{i}, V_{1}=0$ & $V_{3}=0, V_{2}=V_{i}, V_{1}=0$ \\
\hline & $H_{0 \mathrm{BP}}=\frac{-R_{4}}{R_{3}}$ & $H_{0 \mathrm{BP}}=\frac{-R_{4}}{2 R_{3}}$ \\
\hline BS & $\begin{array}{c}V_{3}=V_{i}, V_{2}=0, V_{1}=V_{i} \\
R_{1}=R_{2} \\
H_{0 \mathrm{BS}}=1\end{array}$ & $\begin{array}{c}V_{3}=V_{i}, V_{2}=0, V_{1}=V_{i} \\
R_{1}=R_{2} \\
H_{0 \mathrm{BS}}=1\end{array}$ \\
\hline AP & $\begin{array}{c}V_{3}=V_{2}=V_{1}=V_{i} \\
R_{1}=R_{2}, R_{3}=R_{4} \\
\end{array}$ & $\begin{aligned} V_{3}= & V_{2}=V_{1}=V_{i} \\
R_{1}= & R_{2}, R_{3}=R_{4} / 2 \\
& H_{0 \mathrm{AP}}=1\end{aligned}$ \\
\hline & $\begin{array}{r}1 \\
\end{array}$ & 1 \\
\hline$\omega_{o}$ & $\sqrt{C_{1} C_{2} R_{1} R_{3}}$ & $\sqrt{\sqrt{C_{1} C_{2} R_{1} R_{3}}}$ \\
\hline$Q$ & $R_{4} \sqrt{\frac{C_{1}}{C_{2} R_{1} R_{3}}}$ & $\frac{R_{4}}{2} \sqrt{\frac{C_{1}}{C_{2} R_{1} R_{3}}}$ \\
\hline BW & $\frac{1}{C_{1} R_{4}}$ & $\frac{2}{C_{1} R_{4}}$ \\
\hline
\end{tabular}

Circuit 1. The nonideal expression for the output voltage is found to be

$$
\begin{aligned}
V_{o}=( & V_{3}\left\{\frac{C_{1} \alpha_{2}}{\left(C_{1}+C_{z}\right)}\left(s^{2}+\frac{s}{\left(C_{2}+C_{z}\right) R_{z}}\right)\right\} \\
& -V_{2}\left\{\frac{s \alpha_{1} \alpha_{2} \beta_{n 2} C_{2}}{\left(C_{1}+C_{z}\right)\left(C_{2}+C_{z}\right) R_{3}}\right\} \\
& \left.+V_{1}\left\{\frac{\alpha_{1} \alpha_{2} \beta_{n 1} \beta_{n 2}}{\left(C_{1}+C_{z}\right)\left(C_{2}+C_{z}\right) R_{2} R_{3}}\right\}\right) \\
\times & \left(s^{2}+s\left\{\frac{1}{\left(C_{1}+C_{z}\right)}\left(\frac{\alpha_{2} \beta_{n 2}}{R_{4}}+\frac{1}{R_{z}}\right)+\frac{1}{\left(C_{2}+C_{z}\right) R_{z}}\right\}\right. \\
& \left.+\left\{\frac{1}{\left(C_{1}+C_{z}\right)\left(C_{2}+C_{z}\right)}\left(\frac{\alpha_{1} \alpha_{2} \beta_{p 1} \beta_{n 2}}{R_{1} R_{3}}+\frac{\alpha_{2} \beta_{n 2}}{R_{4} R_{z}}+\frac{1}{R_{z}^{2}}\right)\right\}\right)^{-1} .
\end{aligned}
$$

From (3), the filter parameters $\omega_{0}$ and $\omega_{o} / Q_{o}$ are given by

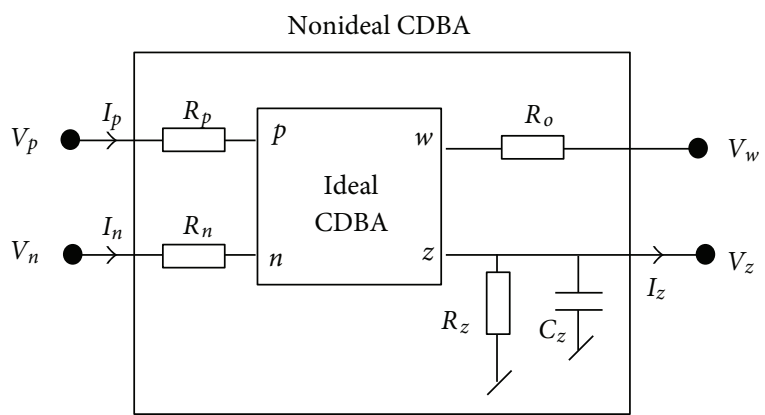

FIgURE 4: Nonideal CDBA showing its parasitic impedances.

$$
\begin{gathered}
\omega_{0}=\sqrt{\frac{1}{\left(C_{1}+C_{z}\right)\left(C_{2}+C_{z}\right)}\left(\frac{\alpha_{1} \alpha_{2} \beta_{p 1} \beta_{n 2}}{R_{1} R_{3}}+\frac{\alpha_{2} \beta_{n 2}}{R_{4} R_{z}}+\frac{1}{R_{z}^{2}}\right)} \\
\frac{\omega_{0}}{Q_{0}}=\frac{1}{\left(C_{1}+C_{z}\right)}\left(\frac{\alpha_{2} \beta_{n 2}}{R_{4}}+\frac{1}{R_{z}}\right)+\frac{1}{\left(C_{2}+C_{z}\right) R_{z}} .
\end{gathered}
$$

Circuit 2. The nonideal expression for the output voltage is found to be 


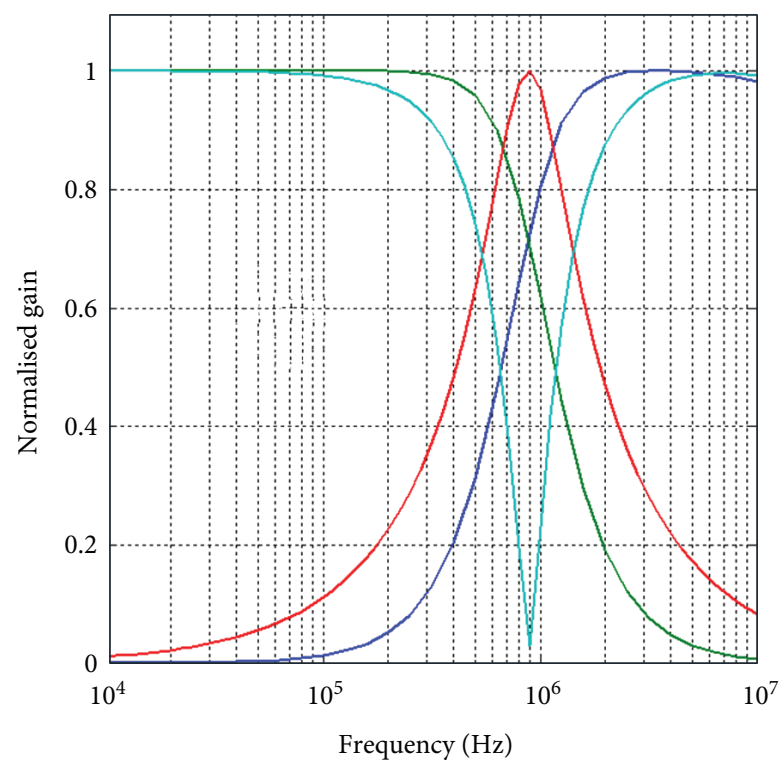

- $\mathrm{HPF}-\mathrm{BPF}$

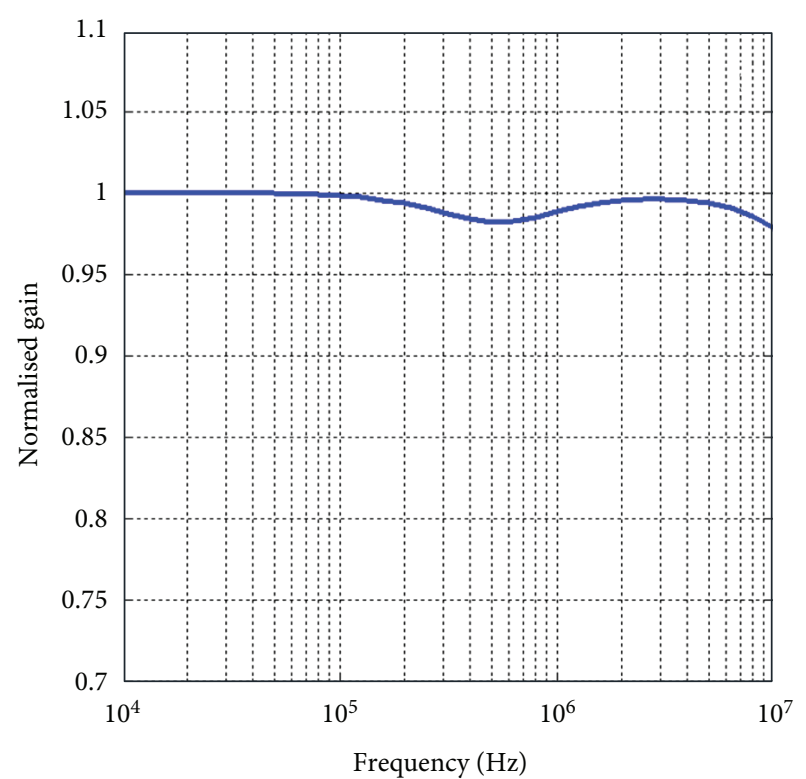

- APF

(a)

(b)

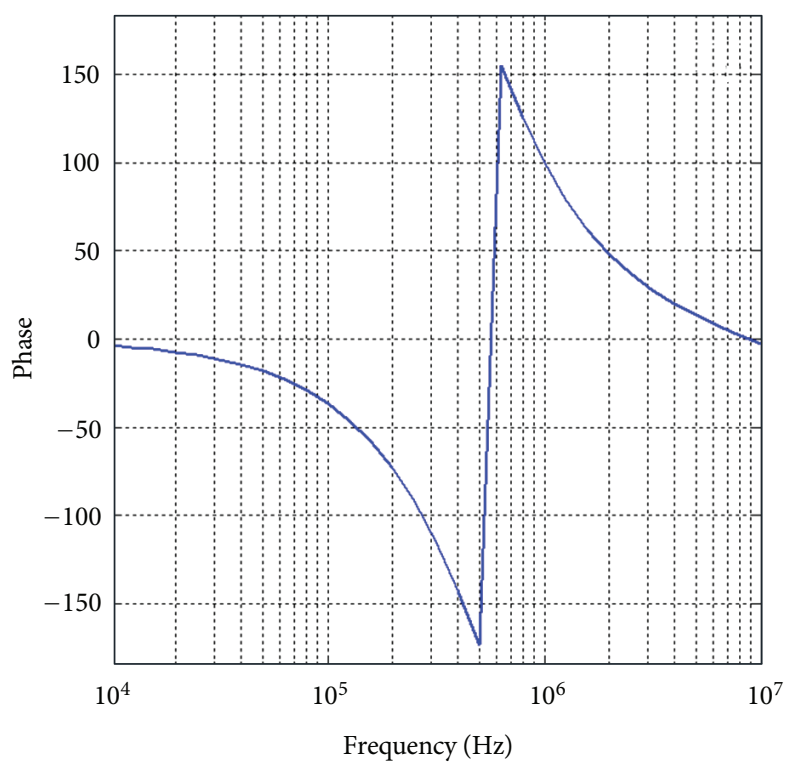

- APF

(c)

FIGURE 5: SPICE simulation results of the frequency response of proposed VMUF Circuit 1. (a) Magnitude response of LP, HP, BP, and BS filters. (b) Magnitude response of AP filter (c) Phase response of AP.

$$
\begin{aligned}
V_{o}=( & V_{3}\left\{\frac{C_{1} \alpha_{2}}{\left(C_{1}+C_{z}\right)}\left(s^{2}+\frac{s}{\left(C_{2}+C_{z}\right) R_{z}}\right)\right\} \\
& -V_{2}\left\{\frac{s \alpha_{1} \alpha_{2} \beta_{n 2} C_{2}}{\left(C_{1}+C_{z}\right)\left(C_{2}+C_{z}\right) R_{3}}\right\} \\
+ & \left.V_{1}\left\{\frac{\alpha_{1} \alpha_{2} \beta_{p 1} \beta_{p 2}}{\left(C_{1}+C_{z}\right)\left(C_{2}+C_{z}\right) R_{2} R_{3}}\right\}\right)
\end{aligned}
$$

$$
\begin{aligned}
& \times\left(s^{2}+s\left\{\frac{1}{\left(C_{1}+C_{z}\right)}\left(\frac{1+\beta_{n 2}}{R_{4}}+\frac{1}{R_{z}}\right)+\frac{1}{\left(C_{2}+C_{z}\right) R_{z}}\right\}\right. \\
& \left.\quad+\left\{\frac{1}{\left(C_{1}+C_{z}\right)\left(C_{2}+C_{z}\right)}\left(\frac{\alpha_{1} \alpha_{2} \beta_{p 1} \beta_{n 2}}{R_{1} R_{3}}+\frac{1+\beta_{n 2}}{R_{4} R_{z}}+\frac{1}{R_{z}^{2}}\right)\right\}\right)^{-1} .
\end{aligned}
$$

From (5), the filter parameters $\omega_{0}$ and $\omega_{0} / Q_{0}$ are given by 


$$
\begin{gathered}
\omega_{o}=\sqrt{\frac{1}{\left(C_{1}+C_{z}\right)\left(C_{2}+C_{z}\right)}\left(\frac{\alpha_{1} \alpha_{2} \beta_{p 1} \beta_{n 2}}{R_{1} R_{3}}+\frac{\left(1+\beta_{n 2}\right)}{R_{4} R_{z}}+\frac{1}{R_{z}^{2}}\right)}, \\
\frac{\omega_{0}}{Q_{0}}=\frac{1}{\left(C_{1}+C_{z}\right)}\left(\frac{\left(1+\beta_{n 2}\right)}{R_{4}}+\frac{1}{R_{z}}\right)+\frac{1}{\left(C_{2}+C_{z}\right) R_{z}} .
\end{gathered}
$$

From the previous nonideal expressions, the following may now be noted that due to nonunity of current and voltage gains and parasitic capacitances, the practically realized $\omega_{0}$ and $\omega_{0} / Q_{0}$ will be somewhat different than their ideal values as is evident from (4) and (6). The errors on these parameters can be kept small by choosing the external capacitances $C_{1}$, $C_{2} \gg C_{z}$, and external resistors $R_{1}, R_{2}, R_{3}, R_{4} \ll R_{z}$. Alternatively, if the values of current gains and voltage gain and parasitic elements $R_{z}$ and $C_{z}$ are known, then (4) and (6) can be used to achieve a predistorted design.

\section{Spice Simulation Results}

To verify the theoretical results, both of the proposed CDBAbased VMUF circuits of Figure 3 have been simulated in PSPICE using macro model of commercially available AD844 ICs employed to construct the CDBAs according to the schematic of Figure 2 with DC bias supply voltages of $\pm 12 \mathrm{~V}$. Both circuits have been found to function as predicted by theory.

To conserve space, we present here simulation results of only Circuit 1 of Figure 3 (shown in Figure 5) with passive components values chosen as $C_{1}=C_{2}=100 \mathrm{pF}$ (in all responses), $R_{1}=1.59 \mathrm{k} \Omega(\mathrm{LP}, \mathrm{HP}, \mathrm{BP}, \mathrm{BS}), R_{1}=4.75 \mathrm{k} \Omega$ (AP), $R_{2}=1 \mathrm{k} \Omega$ (LP, HP, BP), $R_{2}=1.75 \mathrm{k} \Omega$ (BS), $R_{2}=$ $4.9 \mathrm{k} \Omega$ (AP), $R_{3}=1.59 \mathrm{k} \Omega$ (in all responses), $R_{4}=1.12 \mathrm{k} \Omega$ (LP, HP), $R_{4}=1.59 \mathrm{k} \Omega$ (BP, AP), and $R_{4}=1.43 \mathrm{k} \Omega$ (BS). The simulation results, thus, confirm the validity of the theoretical formulations.

\section{Concluding Remarks}

Two new three-input single-output VMUFs using two CDBAs have been proposed which can realize all the five standard types filter functions with a minimum number of passive components to enable sequential tuning of various filter parameters. The proposed circuits have external resistors going to the input terminals of CDBAs, due to which all the parasitic input resistances of the CDBAs can be easily merged in the external resistors. On the other hand, in both cases, input resistance can be made high by choosing input resistors to be high valued, whereas the output $V_{o}$ is available from a low output impedance node. In contrast to previously known CDBA-based circuit of [6], in the proposed circuits, any additional voltage inversion is not required to realize all pass function, thus resulting in the saving of one active element. PSPICE simulations have verified the workability of the proposed circuits, and exemplary simulation results of one of the proposed configurations have been presented.

\section{Acknowledgment}

This work was performed at Analog Signal Processing Research Lab, NSIT, New Delhi, India.

\section{References}

[1] A. Sedra and K. C. Smith, Microelectronic Circuits, Holt, Rinehart and Winston, Orlando, Fla, USA, 5th edition, 2003.

[2] S. Maheshwari and I. A. Khan, "Novel voltage-mode universal filter using only two CDBAs," Journal of Circuits, Systems and Computers, vol. 14, no. 1, pp. 159-164, 2005.

[3] G. W. Roberts and A. S. Sedra, "All current-mode frequency selective circuits," Electronics Letters, vol. 25, no. 12, pp. 759-761, 1989.

[4] C. Acar and S. Ozoguz, "A new versatile building block: current differencing buffered amplifier suitable for analog signalprocessing filters," Microelectronics Journal, vol. 30, no. 2, pp. 157-160, 1999.

[5] S. Ozoguz, A. Toker, and C. Acar, "Current-mode continuoustime fully-integrated universal filter using CDBAs," Electronics Letters, vol. 35, no. 2, pp. 97-98, 1999.

[6] W. Tangsrirat, T. Pukkalanun, and W. Surakampontorn, "CDBA-based universal biquad filter and quadrature oscillator," Active and Passive Electronic Components, vol. 2008, Article ID 247171, 6 pages, 2008.

[7] W. Tangsrirat and S. Pisitchalermpong, "CDBA-based quadrature sinusoidal oscillator," Frequenz, vol. 61, no. 3-4, pp. 102-104, 2007.

[8] C. Acar and H. Sedef, "Realization of $n$ th-order current transfer function using current-differencing buffered amplifiers," International Journal of Electronics, vol. 90, no. 4, pp. 277-283, 2003.

[9] A. U. Keskin, "Voltage-mode high-Q band-pass filters and oscillators employing single CDBA and minimum number of components," International Journal of Electronics, vol. 92, no. 8, pp. 479-487, 2005.

[10] A. U. Keskin and E. Hancioglu, "Current mode multifunction filter using two CDBAs," AEU-International Journal of Electronics and Communications, vol. 59, no. 8, pp. 495-498, 2005.

[11] J. W. Horng, "CDBA based single resistance controlled quadrature oscillator employing grounded capacitors," IEICE Transactions on Fundamentals of Electronics, Communications and Computer Sciences, vol. E85-A, no. 6, pp. 1416-1419, 2002.

[12] S. Maheshwari and I. A. Khan, "Novel single resistance controlled quadrature oscillator using two CDBAs," Journal of Active and Passive Electronic Devices, vol. 2, pp. 137-142, 2007.

[13] W. Tangsrirat, D. Prasertsom, T. Piyatat, and W. Surakampontorn, "Single-resistance-controlled quadrature oscillator using current differencing buffered amplifiers," International Journal of Electronics, vol. 95, no. 11, pp. 1119-1126, 2008.

[14] K. N. Salama and A. M. Soliman, "Voltage mode KerwinHuelsman-Newcomb circuit using CDBAs," Frequenz, vol. 54, no. 3-4, pp. 90-93, 2000.

[15] U. Çam, "A novel current-mode second-order notch filter configuration employing single CDBA and reduced number of passive components," Computers and Electrical Engineering, vol. 30, no. 2, pp. 147-151, 2004.

[16] A. U. Keskin, "Multi-function biquad using single CDBA," Electrical Engineering, vol. 88, no. 5, pp. 353-356, 2006.

[17] M. Sagbas and M. Köksal, "A new multi-mode multifunction filter using CDBA," in Proceedings of the European Conference on 
Circuit Theory and Design, vol. 2, pp. II/225-II/228, September 2005.

[18] M. Koksal, S. E. Oner, and M. Sagbas, "A new second-order multi-mode multi-funtion filter using a single CDBA," in Proceedings of the European Conference on Circuit Theory and Design Conference Program (ECCTD'09), vol. 2, pp. 699-702, August 2009.

[19] A. Toker, S. Özoguz, O. Cicekoglu, and C. Acar, "Current-mode all-pass filters using current differencing buffered amplifier and a new high-Q bandpass filter configuration," IEEE Transactions on Circuits and Systems II, vol. 47, no. 9, pp. 949-954, 2000.

[20] S. Maheshwari and I. A. Khan, "Current-controlled current differencing buffered amplifier: implementation and applications," Active and Passive Electronic Components, vol. 27, no. 4, pp. 219-227, 2004.

[21] W. Tangsrirat and W. Surakampontorn, "Cascadable multipleinput single-output current-mode universal filter based on current differencing buffered amplifiers," Frequenz, vol. 50, no. 7-8, pp. 152-154, 2006.

[22] W. Tangsrirat, K. Klahan, T. Dumawipata, and W. Surakampontorn, "Low-voltage NMOS-based current differencing buffered amplifier and its application to current-mode ladder filter design," International Journal of Electronics, vol. 93, no. 11, pp. 777-791, 2006.

[23] J. K. Pathak, A. K. Singh, and R. Senani, "Systematic realisation of quadrature oscillators using current differencing buffered amplifiers," IET Circuits, Devices and Systems, vol. 5, no. 3, pp. 203-211, 2011.

[24] D. Biolek and V. Biolkova, "SFG simulation of general ladder filter using CDBAs," in Proceedings of the 16th European Conference on Circuit Theory and Design (ECCTD'03), pp. 385-388, Krakow, Poland, 2003.

[25] M. Siripruchyanun and W. Jaikla, "Current-mode biquadratic filter using DO-CCCDBAs," International Journal of Circuit Theory and Applications, vol. 38, no. 3, pp. 321-330, 2010.

[26] D. Biolek, J. Bajer, V. Biolková, Z. Kolka, and M. Kubíček, "Z copy-controlled gain-current differencing buffered amplifier and its applications," International Journal of Circuit Theory and Applications, vol. 39, no. 3, pp. 257-274, 2011. 

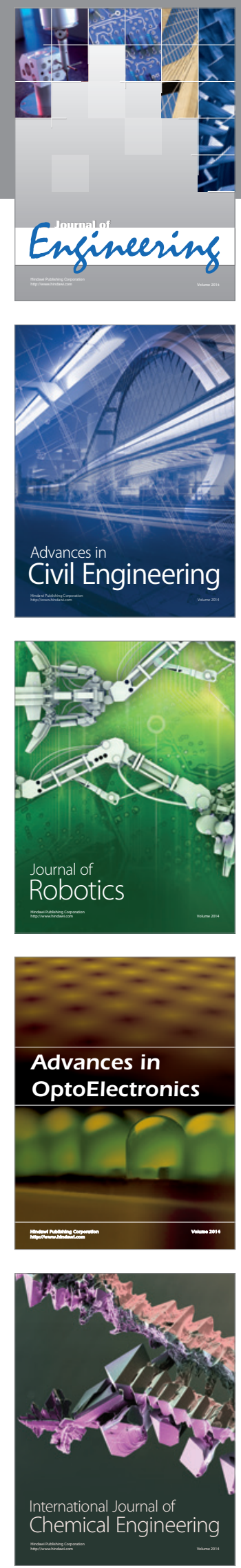

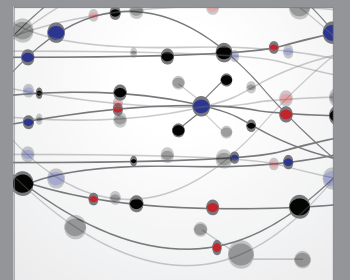

The Scientific World Journal
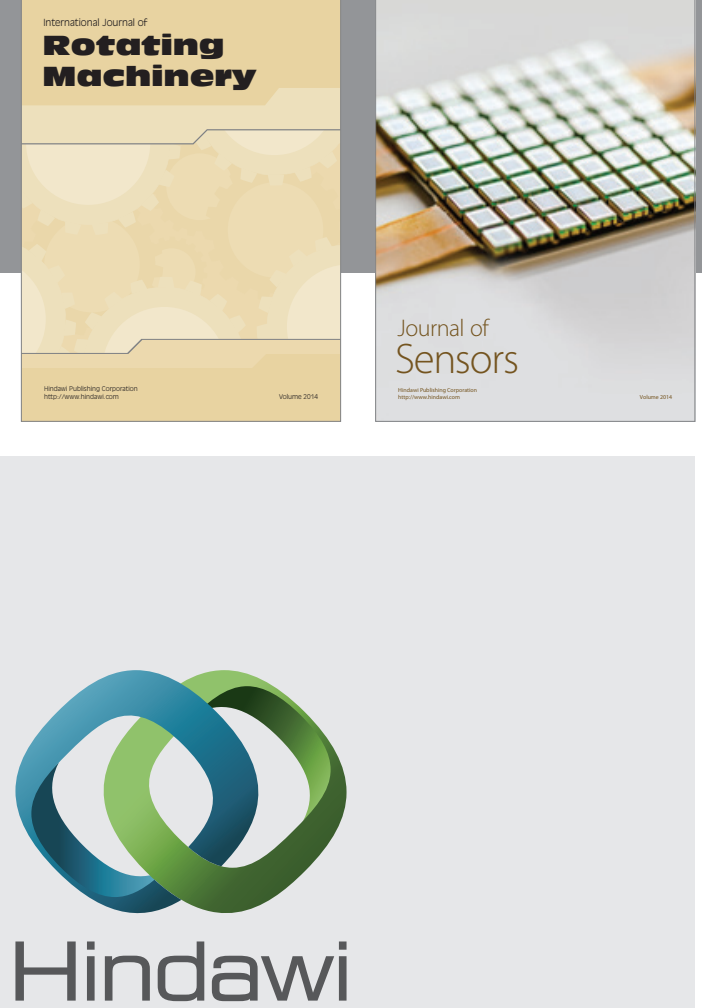

Submit your manuscripts at http://www.hindawi.com
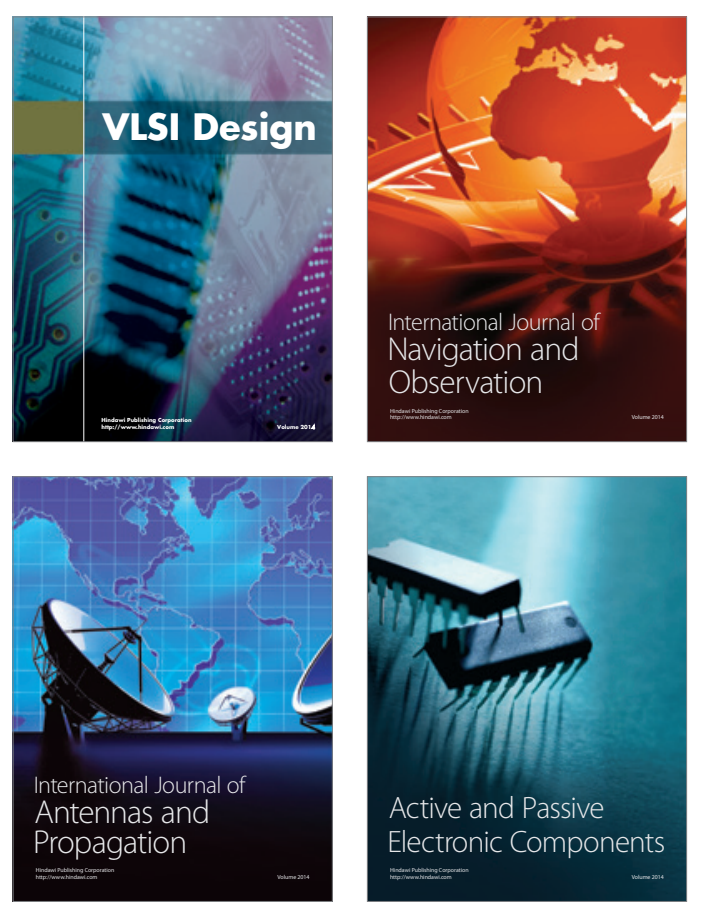
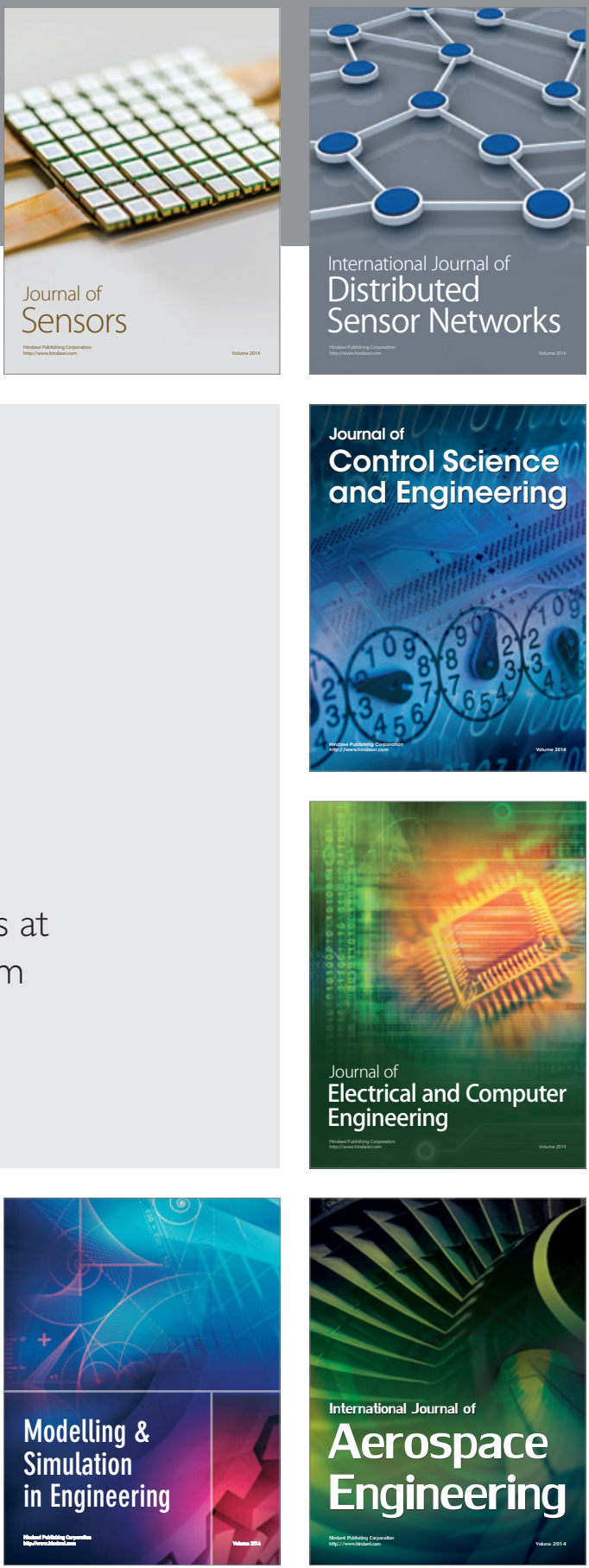

Journal of

Control Science

and Engineering
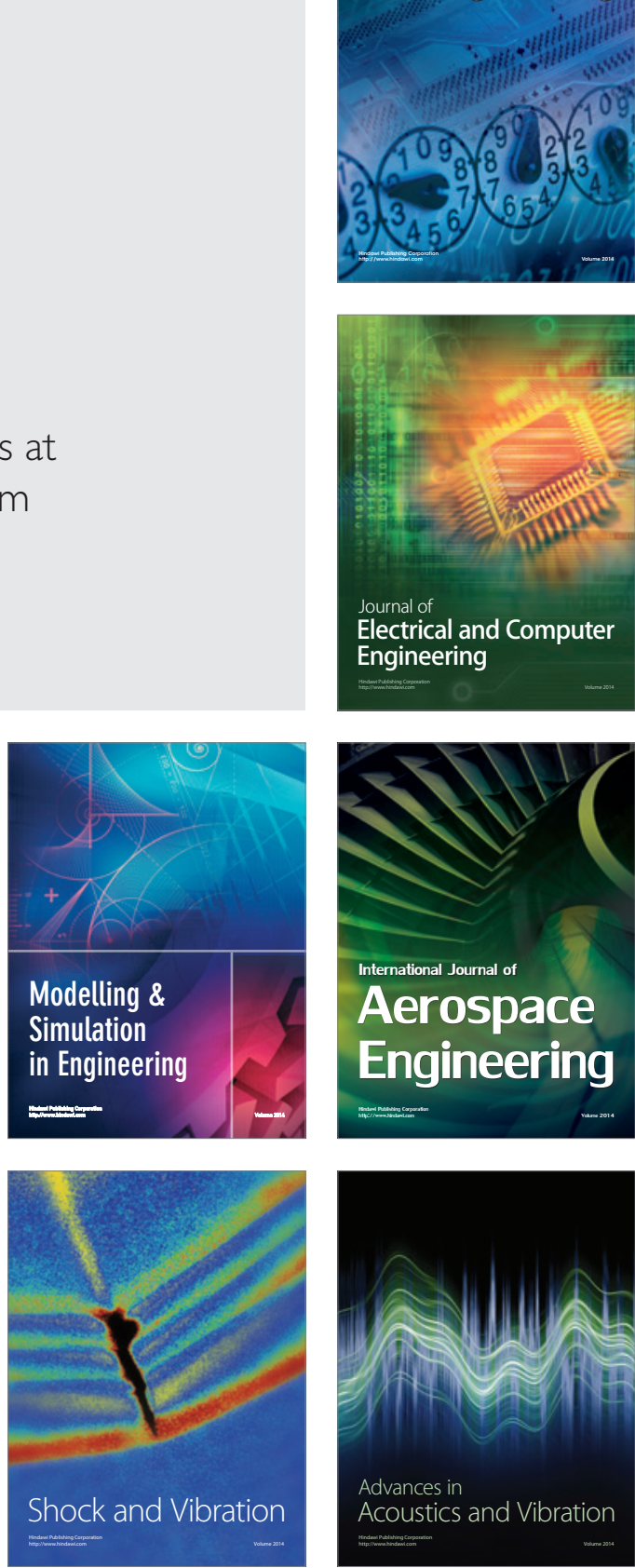